\title{
The Effects of Policy Expectations on Crop SupPLy, with AN A PPLICATION TO BASE UPDATING
}

\author{
Nathan P. Hendricks and Daniel A. Sumner
}

\begin{abstract}
We develop a dynamic model to assess the effects of policy expectations on crop supply and illustrate the approach with estimates of the effects of base updating in U.S. crop programs. For corn and soybeans in the Corn Belt, the effect of base updating is relatively small because relevant crop alternatives are subject to similar policies and the alternatives are substitutes in production. Increasing acreage of one program crop to capture future payments from base updating reduces future payments from the alternative crop. We also use our model to assess the effect of base updating on acreage response to prices.
\end{abstract}

Key words: agricultural policy, base updating, decoupled payments.

JEL codes: Q18.

Expectations of policies affect the economic responses to those policies. This intuitive notion was formalized by Kydland and Prescott (1977), who showed that it was not optimal for policymakers to determine a future set of policies based on the economic response to each policy because individuals adjust their behavior based on their expectation of subsequent policy changes. Of course, farmers are also likely to adjust their behavior to expectations of evolving agricultural policy.

The effect of expected future policies on farm production has been examined recently in the context of programs for which the amount of farm subsidy is not tied directly to current production, but rather to some historical base production. However, if current production may become the base from which subsidies are calculated, current production may affect future payments, and this recognition means that the future base calculation affects the payoff to current production. For

\footnotetext{
Nathan P. Hendricks is an assistant professor in the Department of Agricultural Economics at Kansas State University. Daniel A. Sumner is the Frank H. Buck, Jr., Professor in the Department of Agricultural and Resource Economics at the University of California, Davis, the Director of the University of California, Agricultural Issues Center, and a member of the Giannini Foundation of Agricultural Economics. The authors thank the editor, two anonymous reviewers, David Kling, and Jeff Peterson for helpful comments. Correspondence may be sent to: nph@ksu.edu.
}

example, direct and counter-cyclical payments for program crops in the United States have been calculated according to historical planting and yields (i.e., the crop "base"), so that current production does not affect current program payments. Farmers, however, may anticipate that current production will affect future program payments due to future policy changes through base updating. Indeed, the 2002 Farm Bill did allow farms to update their base to more recent acreage and yields. Farmers who expected future updates would naturally alter their production plans in response to how much such an anticipated update raised the expected present value of per unit revenue (Sumner 2003). Production distortions from these dynamic considerations are similar to previous programs where farm payments were tied to a moving average of historical planted acreage (de Gorter and Fisher 1993).

Recent articles have attempted to model the effect of expected base updating for a single program crop on current production (e.g., McIntosh, Shogren, and Dohlman 2007; Bhaskar and Beghin 2010). However, such studies that model the effect of expectations about policy changes by considering a single crop neglect the full set of policy expectations that affect production of that crop, just as models that ignore cross-price effects neglect the full set of incentives that affect production decisions. For example, if farmers 
expect that the base will be updated for one program crop, then they will likely expect that base to be updated for other relevant program crops. Further, if the program crops are substitutes or complements in production, then the production of one will also be affected by the expectation of base updating of the related crops.

In this paper, we develop a model of a representative farm that maximizes returns from producing two program crops, including the discounted stream of expected government payments. The farmer chooses the acreage to plant to each crop, where current acreage affects the stream of future government payments through expected base updating. We obtain closed-form solutions for the effect of expected base updating on program crop acreage and the effect of expected base updating on acreage response to market prices.

The effect of expected base updating on acreage depends on the degree to which alternative program crops are substitutes or complements in production, as well as the relative payment rate between program crops. If two program crops are strong substitutes in production, then farmers who expect base updating may actually decrease acreage of the crop with a lower governmental payment rate. Furthermore, in every case, the effect of expected base updating on acreage is overestimated for the crop with a high payment rate if updating for the alternative program crop is ignored. If the alternative crop is a non-program crop that does not result in a loss of payment eligibility, then the effect of expected base updating on the program crop can simply be modeled in a single crop context. If planting the alternative crop results in a loss of payment eligibility, then current payments are already tied directly to the acreage decision (Just and Kropp 2013).

While we illustrate the model and measurements with the case of base updating for direct and counter-cyclical payments in the United States, our results demonstrate the broader principle of the importance of modeling the multicrop nature of agriculture to understand the effect of policy expectations. In general, the total effect of the policy expectation must account for the jointness of agricultural production. So, for example, our results are also relevant to evaluating the production effects of the Single Payment Scheme in Europe, where current payments are also not tied to current production.

We also extend the literature on the production effects of expected policy change by modeling the effect on acreage response to market price. Much of the literature addressing the effect of government programs on supply response to market price has attempted to control for government programs in the econometric analysis (e.g., Houck and Ryan 1972; Lee and Helmberger 1985). McDonald and Sumner (2003) argue that these approaches do not allow recovery of the "structural" supply parameters that are not conditional on existing government programs. Our approach follows that of McDonald and Sumner (2003), who simulate the effect of government programs on supply response-which can then be used to recover the "structural" supply response.

As noted, we provide a closed-form solution, rather than relying on numerical methods to obtain a solution. This makes our results more transparent to assumptions about parameter values. Although we report results for different combinations of parameters, the reader can readily calculate the effect on production with their own assumptions about parameter values. Our results are also not subject to smoothness concerns derived from relying on discrete methods. Bhaskar and Beghin's (2010) stochastic dynamic programming model is sufficiently complicated that they consider only four discrete acreage options each year, which causes them to report results that may be larger or smaller than the true impacts from the model.

We apply our model to the acreage of corn and soybeans in Iowa, Illinois, and Indiana by simulating the effects of expected base updating on acreage and acreage response to market prices across a range of parameter values. We find that expected base updating leads to a small increase in corn acreage and a small decrease in soybean acreage, since the two crops are substitutes in production, and corn has a larger government payment rate per acre. Our results may also be interpreted in light of recent (2012 and 2013) policy discussions. Many corn and soybean growers may now expect that direct payments will be eliminated. Our results indicate that this revision of policy expectations would cause a small decrease in corn acreage and a small increase in soybean acreage. 
We also find that expected base updating dampens both the own-price and cross-price acreage responses.

While we examine the effect of expected base updating on production, we also recognize that a substantial body of literature has identified several other avenues by which current payments that are not tied to current production may distort current production. The increase in a farmer's wealth from government payments may affect production by decreasing risk aversion (e.g., Hennessy 1998; Just 2011; Serra, Goodwin, and Featherstone 2011), easing credit constraints (e.g., Roe, Somwaru, and Diao 2002; Girante, Goodwin, and Featherstone 2008), increasing labor supplied to farming (e.g., Ahearn, El-Osta, and Dewbre 2006; Key and Roberts 2009), and increasing farm survival (Chau and de Gorter 2005). Since counter-cyclical payments depend on prices, they reduce the probability of low returns and may increase acreage for risk averse farmers, or increase available credit (e.g., Hennessy 1998; Antón and Mouël 2004; Lin and Dismukes 2007).

Several studies have attempted to estimate the effect of such payments on production by regressing some measure of production on government payments after correcting for their endogeneity (e.g., Goodwin and Mishra 2006; O'Donoghue and Whitaker 2010; Weber and Key 2012). This direct econometric evidence does not separate production impacts due to expected base updating from production impacts through all other avenues.

\section{Literature Review on the Production Effects of Base Updating}

One example in the literature of policy expectations affecting production is through expected base updating. Direct and countercyclical payments in the United States are calculated according to historical planting and yields (i.e., the crop "base"), so that current production does not affect current program payments. If the government updates base acres in the future, then current planting decisions will affect a farmer's future government payments, which provides an incentive to plant program crops to increase (or not lose) future government payments. The base updating allowed in the 2002 Farm
Bill likely influenced farmers to increase their probability of another update in future legislation, thus creating a stronger link between direct and counter-cyclical payments and production decisions (Sumner 2003).

Coble, Miller, and Hudson (2008) report results from a survey of Iowa and Mississippi farmers. In 2005, farmers believed that they would be able to update base acres in the next farm bill with a $40 \%$ probability, on average. About $4 \%$ of Iowa farmers reported adjusting acreage in anticipation of base updating. Mississippi farmers were more likely to report adjusting acreage, with $10.2 \%$ of soybean farmers and $15.7 \%$ of cotton farmers reporting an adjustment due to an anticipated base update. Goodwin and Mishra (2005) report results from a national survey conducted by USDA that indicate $17.5 \%$ of farmers consider base updating important for their acreage decisions.

McIntosh, Shogren, and Dohlman (2007) conduct an experiment to assess the allocation of "tokens" between a program crop and a non-program crop under price and policy uncertainty with programs designed to be similar to direct and counter-cyclical payments. These authors were unable to find statistically significant evidence that participants allocated more tokens to the base when there was a possibility of updating base. The authors note that their policy uncertainty also included the possibility that the program could be eliminated altogether, which reduced the incentive to increase base for possible updating.

Bhaskar and Beghin (2010) consider a representative Iowa corn farmer who maximizes the expected stream of discounted utility of market returns and government payments that could be affected by base updating. Prices and yield shocks are uncertain. The stochastic dynamic programming model that they construct does not have a closed-form solution, so they solve the model numerically. For their assumed parameters, Bhaskar and Beghin (2010) find that anticipating a voluntary update of base acres in 2007 would increase the average acres planted to corn from 2003 to 2007 by as much as $6.25 \%$. These authors' results also show that the effect on acreage decisions depends on anticipated prices since counter-cyclical payments are only made when prices are low; they do not find any substantial effect of base updating on yields through greater nitrogen application. 


\section{U.S. Farm Commodity Programs}

We develop our model of policy expectations for the case of farm commodity programs in the United States. In particular, we focus on direct and counter-cyclical payments and the effects of expected base updating. Before developing the model, we provide a brief description of the programs.

Direct payments are calculated as:

$$
D P_{t}^{j}=\lambda_{d} D^{j} B Y_{t}^{j} B A_{t}^{j},
$$

where $D P_{t}^{j}$ is the direct payment for crop $j$ in year $t, \lambda_{d}$ is a discount factor for direct payments set by legislation, $D^{j}$ is the direct payment rate set by policy, $B Y_{t}^{j}$ denotes the base yield, and $B A_{t}^{j}$ denotes the base acres. A farmer receives the direct payment if the land is used for agricultural purposes, with the exception of planting almost all fruits, vegetables, melons, tree nuts, and wild rice (Farm Service Agency 2008).

Counter-cyclical payments are triggered when the "effective price" falls below the "target price" for a particular program crop. The amount paid is expressed as

$$
\begin{gathered}
C C P_{t}^{j}=\lambda_{c} \max \left(0, T P^{j}-\max \left(L R^{j}, p_{t}^{j}\right)\right. \\
\left.-D^{j}\right) B Y_{t}^{j} B A_{t}^{j},
\end{gathered}
$$

where $C C P_{t}^{j}$ is the counter-cyclical payment for crop $j$ in year $t, \lambda_{c}$ is a discount factor for counter-cyclical payments set by legislation, $T P^{j}$ is the target price set by policy, $L R^{j}$ is the loan rate set by policy, and $p_{t}^{j}$ is the marketing year average price for crop $j$. The "effective price" is the direct payment rate plus the higher of the loan rate or the market price. As with direct payments, the farmer is eligible to receive counter-cyclical payments if the land is used for agricultural purposes with the same exceptions. For example, if a farmer has corn base and grows soybeans, then the farmer will receive counter-cyclical payments if the effective price of corn falls below the target price for corn. Even if the price of soybeans is high, the farmer will receive counter-cyclical payments based on the payment calculation for corn.
For simplicity, we assume that the discount factor is the same for direct and countercyclical payments $\left(\lambda_{d}=\lambda_{c}=\lambda\right),{ }^{1}$ and that base yields and base acres are the same for direct and counter-cyclical payments. ${ }^{2}$ Adding equations (1) and (2) provides an approximation for the total base payment:

$$
\begin{aligned}
& B P_{t}^{j}=\lambda \max \left(D^{j}, T P^{j}-\max \left(L R^{j}, p_{t}^{j}\right)\right) \\
& B Y_{t}^{j} B A_{t}^{j}=\theta^{j}\left(p_{t}^{j}\right) B Y_{t}^{j} B A_{t}^{j} .
\end{aligned}
$$

The payment rate for base (i.e., payment per bushel of base) is denoted as $\theta^{j}\left(p_{t}^{j}\right)$. Equation (3) provides a stylized representation of the total direct and counter-cyclical payments for our model.

Loan deficiency payments are triggered when market prices fall below the loan rate. Eligible farmers receive the positive difference between a county-specific loan rate and the posted county price-the government's measure of the local market price-multiplied by the farmer's production:

$$
\begin{aligned}
L D P_{t}^{j} & =\max \left(0, L R^{j}-p_{t}^{j}\right) y_{t}^{j} a_{t}^{j} \\
& =\eta^{j}\left(p_{t}^{j}\right) y_{t}^{j} a_{t}^{j},
\end{aligned}
$$

where $L D P_{t}^{j}$ is the loan deficiency payment for crop $j$ in year $t, L R^{j}$ is the loan rate, $p_{t}^{j}$ is the market price (i.e., posted county price), $y_{i t}^{j}$ is the yield, and $a_{i t}^{j}$ represents the planted acres for crop $j$. The payment rate for loan deficiency payments (i.e., payment per bushel of production) is denoted as $\eta^{j}\left(p_{t}^{j}\right)$.

\section{Base Updating in a Multicrop Context}

We develop a stylized model to examine the effect of the probability of base updating occurring on program crop acreage and acreage response to market price. To simplify the exposition, we develop the model with two crops that we refer to as corn and soybeans, since this corresponds directly

\footnotetext{
1 In the 2002 Farm Bill, the discount factor was 0.85 for direct and counter-cyclical payments. The 2008 Farm Bill changed the discount factor to 0.833 for direct payments.

2 Base yield can differ for direct and counter-cyclical payments due to the option to update counter-cyclical payment yields in the 2002 Farm Bill.
} 
to our numerical simulations of corn and soybean production in Iowa, Illinois, and Indiana. Extending the model to other commodity contexts would mean using a different set of parameter values in the numerical simulations-including the addition of other program crops, non-program crops, and crops for which planting is precluded on base acres. Our model is stylized in that we make several simplifying assumptions that allow the model to be tractable and transparent, yet maintain core features of the problem.

\section{Assumptions}

\section{Assumption 1. Risk neutrality.}

This article analyzes how farmers alter their current acreage decisions in order to capture benefits of expected returns from potential base updating in the future. To the extent that base updating also affects the variation in expected returns, then risk averse farmers may alter their current acreage in order to capture benefits from a reduction in the future variation of expected returns as well. Most of the effect of base updating on current acreage decisions is likely to occur through changes in the relative expected returns of alternative crops, rather than through changes in the relative expected variation of returns of alternative crops. Thus, omitting risk aversion is likely to have a negligible impact on our results. Assuming risk neutrality makes an analytical solution to our model much more tractable.

\section{Assumption 2. Yields are stochastic and exogenous.}

We assume that crop yields are uncertain at the time of planting decisions due to weather variability. We treat yields as exogenous-i.e., farmers do not increase expected yields in response to an increase in expected revenue. Although crop yields are affected by several factors that the farmer controls, such as management practices and fertilizer use, it is not clear to what extent farmers make substantial changes in these factors in the short run in response to changes in expected revenue. Indeed, recent econometric evidence on yield response to price is mixed. For example, econometric evidence from Berry and Schlenker (2011) indicates a weak relationship between yields and crop prices, while Goodwin et al. (2012) find a stronger effect. Bhaskar and Beghin's (2010) model of base updating incorporates changes in fertilizer application that a farmer may make in order to alter the crop yield to capture benefits from an update of base yields in the future, but they find a negligible effect of base updating on nitrogen application.

Assumption 3. No dynamic complementarity in production.

For simplicity, we assume that current crop acreage decisions do not affect production in subsequent years. Thus, profit maximization is a static problem in our model, except for the effect of current acreage decisions on future government payments. In many cropping systems there exist incentives to rotate crops that create dynamic complementarity in production (e.g., see Hennessy 2006). Incorporating the dynamic optimization implied by these crop rotation incentives would substantially complicate our model. For example, an increase in corn acreage due to expected base updating may occur by shifting land from a continuous soybean rotation to a corn-soybean rotation; Hendricks, Smith, and Sumner (2013) show that switching these rotations causes a larger increase in corn acreage in the short run than in the long run. In this article, we only examine the change in corn acreage that occurs from moving to the new long-run equilibrium (i.e., steady-state). Our approach to modeling crop rotations in a static, equilibrium framework is similar to Feng and Babcock (2010).

Assumption 4. The aggregate acreage of each crop is the solution to the profit maximization problem of a representative producer. Market returns are concave in the acreage of the two crops and the optimal acreage of each crop is positive.

We view our model of expected profit maximization as a stylized representation of acreage decisions in aggregate, rather than a precise representation of an individual farmer's behavior. Although our stylized model implies symmetry of crossprice effects, we do not impose this symmetry in the numerical simulations. Instead, we use elasticities in the simulations that are representative of recent econometric evidence. In many regions, total land planted to crops changes little. Although our conceptual model does not impose an acreage constraint, it can be informally incorporated into the model by considering plausible elasticities. 
We use elasticity estimates from Hendricks, Smith, and Sumner (2013) in our numerical simulations, and their elasticities reflect very few changes in total land planted to corn and soybeans in Iowa, Illinois, and Indiana.

Assumption 5. The planning horizon incorporates two future farm bills. The first year governed by the next farm bill is denoted $f$, and the first year governed by the farm bill after that is denoted $F$. The timing of the farm bills is known with certainty. The planning horizon ends in year $T$.

We include only the next two farm bills in the model because any potential benefits from updating in farm bills further into the future are largely discounted and are likely to have a negligible impact on current production decisions. Incorporating uncertainty about the timing of the policy changes is left for future research.

Assumption 6. There are three policy scenarios for each farm bill: (a) base acres and base yields are updated for both crops; (b) base acres and base yields are not updated but the programs continue; or (c) direct and counter-cyclical payments are ended for both crops. Farmers assign a probability $\delta$ that base is updated and a probability $\mu$ that the programs are ended.

To simplify the model, we assume there are only three policy scenarios so that we can analyze the effect of the probability of base updating, $\delta$, on production decisions.

Assumption 7. If base updating occurs, then updating is mandatory and the updated base acres are calculated as a linear function of previous planted acres. Updated base yield is not affected by the number of acres previously planted. Base yield is not updated unless base acres are also updated. The rules of base updating are the same in each farm bill. However, updated base acres are calculated using planted acreage from a subset of years governed by the preceding farm bill.

Assumption 7 describes how the base updating is implemented if a farm bill does update base. We do not intend to model the implementation of a specific piece of legislation. For example, we do not attempt to model all of the voluntary updating options that were included in the 2002 Farm Bill. $^{3}$

\footnotetext{
3 See Young et al. (2005) for a description of the voluntary base updating options in the 2002 Farm Bill.
}

Instead, our model is developed to illustrate general principles about the effect of expected policy changes-within the context of base updating-on production in a multicrop system.

We assume that base updating is mandatory. This assumption allows us to solve our model without backward recursion as discussed later in remark 1. Mandatory updating also imposes smoothness on the optimization problem so that we can approximate the effect of base updating using derivatives. If base updating is voluntary, then the optimization function is not smooth because farmers are likely to only update base if it increases their expected direct and counter-cyclical payments. If base updating is voluntary but the state of nature makes it such that it is not profitable for farmers to update, then our results will overestimate the effect of base updating. In our numerical simulations, we find that the effects of expected base updating are small when accounting for the multicrop nature of agriculture, and these results may still overestimate the effect of base updating. We also assume that updated base acres are a linear function of previously planted acres. For example, base acres in the United States are calculated as an average of previously planted acres.

We assume that updated base yield does not depend on the number of acres previously planted to the crop. One potential violation of this assumption is that planting more corn may reduce corn yield due to a "yield drag" of planting corn after corn. Another violation would occur if changing acreage resulted in the crop being planted on soils with a different productivity. These yield effects are likely to have negligible impacts on the effect of base updating on production decisions, so we omit them to simplify the model. Our model allows for the possibility that base yield is not updated when base acres are updated, but base yield is not updated unless base acres are also updated. ${ }^{4}$

Finally, while we assume that the rules of base updating are the same for each farm bill, the period used to update base acres changes. Updated base acres are calculated from a subset of years governed by the preceding farm bill. This means that current planted acreage may be used to update base acres

\footnotetext{
${ }^{4}$ In other words, there is not an incentive to plant a limited number of acres of the crop to increase base yields in an update, while still maintaining previous base acres.
} 
in the next farm bill (farm bill $f$ ), but will not be used to update base acres in the farm bill after the next one (farm bill $F$ ). Current planted acreage affects payments during farm bill $F$ only if base is updated in farm bill $f$ and not updated in farm bill $F$.

\section{Optimization Problem}

A representative farmer chooses the current acreage of two crops to maximize expected market returns, plus government payments in the current year, plus the stream of discounted direct and counter-cyclical payments during future farm bills. The farmer solves the following optimization problem:

$$
\begin{aligned}
\max _{\mathbf{a}_{0}} E_{0}\left\{r\left(\tilde{\mathbf{p}}_{0}, \tilde{\mathbf{y}}_{0}, \mathbf{a}_{0}\right)+\sum_{j \in c, s}\right. \\
\left.\times\left[L \tilde{D} P_{0}^{j}+\tilde{B} P_{0}^{j}\right]+\sum_{t=f}^{T} \sum_{j \in c, s} \beta^{t} \tilde{B} P_{t}^{j}\right\}
\end{aligned}
$$

where $E_{0}$ denotes the expectation formed at the time of planting the current crop, $\mathbf{a}_{0}$ is a vector of the acres planted to each crop in the current year, $\tilde{\mathbf{p}}_{0}$ is a vector of crop prices, $\tilde{\mathbf{y}}_{0}$ is a vector of crop yields, $r(\cdot)$ is the market return from crop production, $\tilde{L} D P_{t}^{j}$ are loan deficiency payments for crop $j$ as in equation (4), $\tilde{B} P_{t}^{j}$ are base payments (direct and counter-cyclical payments) as in equation (3), and $\beta$ is the discount factor. The current year is denoted by $t=0$, the next farm bill begins in $t=f$, and the last year in the planning horizon is $T$. Expected base payments during future farm bills affect the current acreage decision through the possibility of base updating. The two crops are corn $(j=c)$ and soybeans $(j=s)$. The acres, price, and yield of crop $j$ are denoted $a_{t}^{j}, \tilde{p}_{t}^{j}$, and $\tilde{y}_{t}^{j}$ in subsequent derivations. A tilde $(\sim)$ indicates that the variable is stochastic.

There are four stochastic variables for each crop: price, yield, base yield, and base acres. For simplicity, we assume that price and yield distributions are stationary from year to year. Loan deficiency payments are stochastic in equation (5) because prices and yields are stochastic. Base payments are stochastic for two reasons. First, base yield and base acres are known with certainty during the current farm bill, but the payment rate is uncertain because counter-cyclical payments depend on the stochastic market price. Second, base yield and base acres are uncertain during future farm bills because base may be updated in the future farm bill.

Bhaskar and Beghin (2010) argue that only the portion of government payments retained by tenants should be included in the model of acreage decisions. For example, nonfarming landowners may capture a portion of government payments by increasing rent. Nonfarming landowners, however, are likely to influence tenants to make planting decisions such that all government payments are reflected in the acreage decision; thus, we include all government payments in the decision of the representative farmer.

Remark 1. Future decisions do not affect the optimal current acreage from assumptions 3 and 7.

While future government payments affect current acreage decisions through base updating, future decisions themselves do not affect the current acreage decision. Therefore, the solution to the problem does not require backward recursion. Note that in our model the producer does not have control over the decision to update base in future years since we assume mandatory base updating. Therefore, in our model the current acreage decision does not depend on an optimal base updating decision in the future. Furthermore, base payments are completely decoupled in our model, except through base updating, so optimal acreages during future farm bills do not depend on base payments within those years. In other words, the marginal benefit of altering current acreage to increase base payments in the future does not depend on future acreage decisions. We show explicitly in the online appendix that writing the model as a Bellman equation simplifies to the model in equation (5) under our assumptions.

Several assumptions are required for future decisions to not affect the optimal current acreage. First, we assume no dynamic complementarity in production (assumption 3). Second, we assume that base updating is mandatory (assumption 7). Third, we assume that base acres are updated as a linear function of historical planted acres, so marginal government benefits-if base updating occurs-do not depend on acreage in other years (assumption 7).

Bhaskar and Beghin (2010) solve their model with backward recursion because they 
allow for voluntary base updating. In this model, the marginal benefits of altering current acreage to increase base payments in the future depends on the farmer's decision of whether or not to update base in the future, which is affected by the state of nature. Our assumption of mandatory base updating simplifies the problem and may lead us to overstate the effect of base updating, even though our numerical simulations indicate small effects of base updating. The authors de Gorter and Fisher (1993) evaluate a program where current planted acreage only affects future government payments if the farmer diverts acreage in the future. Therefore, future decisions affect the optimal current acreage in the models of Bhaskar and Beghin (2010) and de Gorter and Fisher (1993).

We distribute the expectation operator through the summation in (5). In remark 2 , we define the form of the expected base payments during each farm bill.

Remark 2. From assumptions 5, 6, and 7 we can write the expected value of base payments for crop $j$ during each of the farm bills as follows: in the current year $(t=0)$ expected base payments are:

$$
E_{0} \tilde{B} P_{t}^{j}=E_{0} \theta^{j}\left(\tilde{p}_{t}^{j}\right) B Y_{0}^{j} B A_{0}^{j},
$$

while under the next farm bill $(t=f, \ldots$, $F-1)$, expected base payments are

$$
\begin{aligned}
E_{0} \tilde{B} P_{t}^{j}= & \delta E_{0} \theta^{j}\left(\tilde{p}_{t}^{j}\right) B Y_{f}^{j} B A_{f}^{j}\left(a_{f-}^{j}\right) \\
& +(1-\mu-\delta) E_{0} \theta^{j}\left(\tilde{p}_{t}^{j}\right) \\
& \times B Y_{0}^{j} B A_{0}^{j},
\end{aligned}
$$

and under the farm bill after the next one $(t=F, \ldots, T)$, expected base payments are:

$$
\begin{aligned}
E_{0} \tilde{B} P_{t}^{j}= & \delta^{2} E_{0} \theta^{j}\left(\tilde{p}_{t}^{j}\right) B Y_{F}^{j} B A_{F}^{j}\left(a_{F-}^{j}\right) \\
& +\delta(1-\mu-\delta) E_{0} \theta^{j}\left(\tilde{p}_{t}^{j}\right) B Y_{f}^{j} B A_{f}^{j} \\
& \times\left(a_{f-}^{j}\right)+(1-\mu-\delta) \delta E_{0} \theta^{j}\left(\tilde{p}_{t}^{j}\right) \\
& \times B Y_{F}^{j} B A_{F}^{j}\left(a_{F-}^{j}\right)+(1-\mu-\delta)^{2} \\
& \times E_{0} \theta^{j}\left(\tilde{p}_{t}^{j}\right) B Y_{0}^{j} B A_{0}^{j} .
\end{aligned}
$$

Expression $E_{0} \theta^{j}\left(\tilde{p}_{t}^{j}\right)$ is the expected payment rate on base yield and base acres from equation (3). Expected base payments under the current farm bill in equation (6) depend on a fixed base yield $\left(B Y_{0}^{j}\right)$ and base acres $\left(B A_{0}^{j}\right)$.

Expected base payments under the next farm bill (farm bill $f$ ) in equation (7) are the sum of base payments under different policy scenarios weighted by the probability of each scenario. The three policy scenarios are as follows: $(a)$ with probability $\delta$, base is updated to a new base yield $\left(B Y_{f}^{j}\right)$ and base acres $\left(B A_{f}^{j}\right)$; $(b)$ with probability $1-\mu-\delta$, the current programs continue without base updating, or $(c)$ with probability $\mu$, programs are ended and there are no direct or counter-cyclical payments. From assumption 7, updated base acres are a function of the acres planted in years immediately prior to the new farm bill (denoted $\left.a_{f-}^{j}\right)$. We assume that planted acres in the current period $\left(a_{0}^{j}\right)$ are included in the calculation of updated base acres in the next farm bill. From assumption 7, updated base yield is not a function of previous acreage. We assume that updated base yield is independent of future market prices. In principle, there is likely a correlation between the historical average of farm-level yields and market prices during the future farm bills, but such a correlation is likely small and would have a negligible effect on our numerical simulations.

To model expected base payments under the farm bill after the next one (farm bill $F$ ) in equation (8), we consider the joint distribution of potential policy outcomes from the two future farm bills. In the first term, base is updated in both farm bills with joint probability $\delta^{2}$. In the second term, base is updated in farm bill $f$ but not farm bill $F$ with joint probability $\delta(1-\mu-\delta)$. In the third term, base is not updated in farm bill $f$, but is updated in farm bill $F$ with joint probability $(1-\mu-\delta) \delta$. In the fourth term, base is not updated in either farm bill with joint probability $(1-\mu-\delta)^{2}$. There are no base payments in farm bill $F$ if direct and counter-cyclical payments are ended in either farm bill. If base acres are updated in farm bill $F$, then base acres are a function of acres planted in years immediately prior to the farm bill (denoted $a_{F-}^{j}$ ). Planted acres in the current period $\left(a_{0}^{j}\right)$ are not included in the calculation of updated base acres in farm bill $F$. 
After substituting equations (6)-(8) into the optimization problem in (5), we derive the following first order conditions for the optimal corn and soybean acreage in the current year:

$$
\begin{aligned}
& \frac{\partial E_{0} r(\cdot)}{\partial a_{0}^{j}}+E_{0} \eta^{j}\left(\tilde{p}_{0}^{j}\right) \tilde{y}_{0}^{j}+\delta \Psi_{f}^{j} \\
& \quad+\delta(1-\mu-\delta) \Psi_{F}^{j}=0, \quad \forall j \in\{c, s\}
\end{aligned}
$$

where

$$
\Psi_{f}^{j}=\sum_{t=f}^{F-1} \beta^{t} E_{0} \theta^{j}\left(\tilde{p}_{t}^{j}\right) B Y_{f}^{j} \frac{\partial B A_{f}^{j}}{\partial a_{0}^{j}},
$$

and

$$
\Psi_{F}^{j}=\sum_{t=F}^{T} \beta^{t} E_{0} \theta^{j}\left(\tilde{p}_{t}^{j}\right) B Y_{f}^{j} \frac{\partial B A_{f}^{j}}{\partial a_{0}^{j}} .
$$

The term $\frac{\partial E_{0} r(\cdot)}{\partial a_{0}^{j}}$ denotes marginal expected market returns (i.e., marginal expected market revenue minus the marginal expected cost of production). The term $E_{0} \eta^{j}\left(\tilde{p}_{0}^{j}\right) \tilde{y}_{0}^{j}$ denotes marginal expected loan deficiency payments, while $\Psi_{f}^{j}$ is the present value of additional government payments during farm bill $f$ from planting another acre of crop $j$ in the current year if base is updated in farm bill $f$. Further, $\Psi_{F}^{j}$ is the present value of additional government payments during farm bill $F$ from planting another acre of crop $j$ in the current year if base is updated in farm bill $f$, but is not updated in farm bill $F$. Note that current acreage does not affect government payments during farm bill $F$ if base is updated in farm bill $F\left(\frac{\partial B A_{F}^{j}}{\partial a_{0}^{j}}=0\right)$. The expression $\delta \Psi_{f}^{j}+\delta(1-\mu-\delta) \Psi_{F}^{j}$ represents the expected present value of marginal government payments from base updating. Thus, the optimal acreage will be such that the marginal expected market returns plus marginal expected loan deficiency payments, plus the present value of marginal expected government payments from base updating equals zero for each crop.

Before examining the effect of expected base updating on acreage decisions, we define the structural acreage elasticity.
Definition 1. The structural corn acreage elasticities are movements along the marginal cost function in the absence of government distortions:

$$
\begin{aligned}
\varepsilon^{c c} & =-\frac{\partial^{2} E_{0} r(\cdot)}{\partial a_{0}^{s} \partial a_{0}^{s}} \frac{\bar{p}^{c} \bar{y}^{c}}{|H| \bar{a}^{c}} \\
\varepsilon^{c s} & =\frac{\partial^{2} E_{0} r(\cdot)}{\partial a_{0}^{c} \partial a_{0}^{s}} \frac{\bar{p}^{s} \bar{y}^{s}}{|H| \bar{a}^{c}}
\end{aligned}
$$

where the elasticity is evaluated at average prices $\left(\bar{p}^{j}\right)$, yields $\left(\bar{y}^{j}\right)$, and acreage $\left(\bar{a}^{c}\right)$. The determinant of the Hessian is denoted $|H|$ and is positive by the second order condition for profit maximization.

The derivation of the structural acreage elasticities is standard for profit maximization with two outputs, except that prices and yields are stochastic. In the absence of government distortions, the farmer maximizes expected market returns,

$$
\begin{aligned}
& \max _{\mathbf{a}_{0}} E_{0} r\left(\tilde{\mathbf{p}}_{0}, \tilde{\mathbf{y}}_{0}, \mathbf{a}_{0}\right) \\
& \quad=E_{0}\left[\tilde{p}_{0}^{c} \tilde{y}_{0}^{c} a_{0}^{c}+\tilde{p}_{0}^{s} \tilde{y}_{0}^{s} a_{0}^{s}-\operatorname{cost}\left(a_{0}^{c}, a_{0}^{s}\right)\right],
\end{aligned}
$$

where cost $(\cdot)$ is the cost function. Note that (14) is a static maximization problem since we assume there is no dynamic complementarity in production (assumption 3 ). We distribute the expectation operator and write $E_{0}\left(\tilde{p}_{0}^{j} \tilde{y}_{0}^{j}\right)=E_{0}\left(\tilde{p}_{0}^{j}\right) E_{0}\left(\tilde{y}_{0}^{j}\right)+\operatorname{Cov}\left(\tilde{p}_{0}^{j}, \tilde{y}_{0}^{j}\right)$ from the definition of covariance. The first order conditions that define optimal acreage in the absence of government programs are:

$$
\begin{aligned}
\frac{\partial E_{0} r(\cdot)}{\partial a_{0}^{j}} & =p_{0}^{j} y_{0}^{j}+\operatorname{Cov}\left(\tilde{p}_{0}^{j}, \tilde{y}_{0}^{j}\right)-\frac{\partial \cos t}{\partial a_{0}^{j}} \\
& =0, \quad \forall j \in\{c, s\},
\end{aligned}
$$

where $p_{0}^{j}$ is the expected price of crop $j$ at the time of planting in the current year, and $y_{0}^{j}$ is the expected yield. We assume that the expected covariance of price and yield does not depend on the expected price $\left(\frac{\partial \operatorname{Cov}\left(\tilde{p}_{0}^{j}, \tilde{y}_{0}^{j}\right)}{\partial p_{0}^{j}}=0\right)$. The structural corn acreage elasticities in (12) and (13) are obtained by applying the implicit function theorem to the system of equations in (15) (see online appendix for derivation). 


\section{Effect of Base Updating on Acreage}

First we examine the effect of base updating on acreage, where we approximate the percentage change in acreage due to expected base updating by using the midpoint rule as a numerical approximation. The midpoint rule states that acreage with the probability of base updating equal to $\bar{\delta}$ equals the acreage with a zero probability of base updating, plus $\bar{\delta}$ multiplied by the change in acreage from a change in the probability of base updating evaluated at $\bar{\delta} / 2$, which can be written as $a_{0}^{c}(\bar{\delta})=a_{0}^{c}(0)+\bar{\delta} \frac{\partial a_{0}^{c}}{\partial \delta}\left(\frac{\bar{\delta}}{2}\right)$. Rearranging the midpoint rule provides the change in acres planted to corn relative to the average acres planted to corn (i.e., percentage change) if the probability of base updating occurring is $\bar{\delta}$ instead of zero,

$$
\alpha^{c}=\frac{a_{0}^{c}(\bar{\delta})-a_{0}^{c}(0)}{\bar{a}^{c}}=\frac{\bar{\delta}}{\bar{a}^{c}} \frac{\partial a_{0}^{c}}{\partial \delta}\left(\frac{\bar{\delta}}{2}\right) .
$$

The derivative of corn acreage with respect to the probability of base updating is found by applying the implicit function theorem to the system of equations in (9). Plugging the derivative into the numerical approximation of (16) provides an approximation for the percentage change in corn acreage due to expected base updating (see online appendix for derivation):

$$
\begin{aligned}
\alpha^{c}= & \varepsilon^{c c} \frac{\bar{\delta} \Psi_{f}^{c}+\bar{\delta}(1-\mu-\bar{\delta}) \Psi_{F}^{c}}{\bar{p}^{c} \bar{y}^{c}} \\
& +\varepsilon^{c s} \frac{\bar{\delta} \Psi_{f}^{s}+\bar{\delta}(1-\mu-\bar{\delta}) \Psi_{F}^{s}}{\bar{p}^{s} \bar{y}^{s}},
\end{aligned}
$$

where $\Psi_{f}^{j}$ and $\Psi_{F}^{j}$ are defined in equations (10) and (11). The numerator in the first term provides the present value of expected marginal government revenue of corn acres during the next two farm bills with a probability of base updating of $\delta=\bar{\delta}$. This is divided by the marginal market revenue to provide the relative increase in expected marginal revenue from expected base updating. The expected increase in marginal revenue is translated into an acreage effect through the structural own-price elasticity. Similarly, the second term translates the expected increase in marginal revenue for soybeans due to expected base updating into an acreage effect through the structural cross-price elasticity. ${ }^{5}$

The change in corn acreage due to expected base updating can be interpreted as the change in acres compared to a scenario of no base updating, where direct and counter-cyclical payments are expected to continue $(\bar{\delta}=0, \mu=0)$, or this change can be compared to a scenario where direct and counter-cyclical payments are expected to end $(\bar{\delta}=0, \mu=1)$. In both of these scenarios, the probability of base updating is zero.

Since we assume that base is updated for both crops if a farm bill updates base, the total effect of base updating on corn acreage is the sum of two effects: the effect due to an increase in marginal revenue for corn acres, and the effect due to an increase in marginal revenue for soybean acres. Neglecting to account for the loss of base of the alternative program crop overestimates the effect of base updating on acreage if the two program crops are substitutes (negative cross-price elasticity), and underestimates the effect of base updating on acreage if the two program crops are complements (positive cross-price elasticity).

The effect of expected base updating on program crop acreage depends on the relative size of government payments between the alternative land uses and the magnitude of the cross-price elasticity relative to the own-price elasticity. Farmers will seek to increase the acreage of the crop with a relatively large payment rate. The effect of base updating on acreage may even be negative if the program crops are strong substitutes in production and the expected government payment of the alternative crop is relatively large.

We can express the percentage change in acreage due to expected base updating relative to the structural own-price elasticity to provide a measure of the degree of coupling of direct and counter-cyclical payments,

$$
\begin{aligned}
\frac{\alpha^{c}}{\varepsilon^{c c}}= & \frac{\bar{\delta} \Psi_{f}^{c}+\bar{\delta}(1-\mu-\bar{\delta}) \Psi_{F}^{c}}{\bar{p}^{c} \bar{y}^{c}} \\
& +\frac{\varepsilon^{c s}}{\varepsilon^{c c}} \frac{\bar{\delta} \Psi_{f}^{s}+\bar{\delta}(1-\mu-\bar{\delta}) \Psi_{F}^{s}}{\bar{p}^{s} \bar{y}^{s}}
\end{aligned}
$$

\footnotetext{
5 Our model is similar to equilibrium displacement models or Muth models (Muth 1964) in that we estimate the percentage change in quantity from an exogenous factor using elasticity parameters to approximate the market response.
} 
In other words, equation (18) indicates the percentage change in acreage due to expected base updating relative to the percentage change in acreage from a 100\% increase in the price of corn. Note that our measure of coupling is different from estimates that indicate the change in acreage due to a change in direct and counter-cyclical payments (e.g., econometric estimates).

\section{Effect of Base Updating on Response to Market Price}

Next, the effect of base updating on acreage response to market price is considered. We derive the acreage response to price in the presence of government payments, then compare the magnitude of this response relative to structural elasticities. We consider the cases where changes in market prices are perceived to be transitory or permanent. If farmers perceive a change in market price in the current year to be transitory, then they expect price to resume to some long-run mean in future years. If farmers perceive a change in market price in the current year to be permanent, then they expect the mean price to remain at the new level in future years. ${ }^{6}$

Case 1. If changes in market prices in the current year are perceived to be transitory, then the acreage elasticities with respect to market prices in the presence of government payments (denoted $\hat{\varepsilon}^{c c}$ and $\hat{\varepsilon}^{c s}$ ) relative to the structural elasticities are as follows (see online appendix for derivation):

$$
\begin{aligned}
& \frac{\hat{\varepsilon}^{c c}}{\varepsilon^{c c}}=1+\frac{\partial E_{0} \eta^{c}\left(\tilde{p}_{0}^{c}\right)}{\partial p_{0}^{c}}, \\
& \frac{\hat{\varepsilon}^{c s}}{\varepsilon^{c s}}=1+\frac{\partial E_{0} \eta^{s}\left(\tilde{p}_{0}^{s}\right)}{\partial p_{0}^{s}},
\end{aligned}
$$

where $p_{0}^{j}$ is the expected price of crop $j$ at the time of planting in the current year.

In case 1 , the derivatives are only with respect to a change in the expected price in the current year, since the change in price is transitory. Expected base updating has no effect on the response to market prices

\footnotetext{
${ }^{6}$ To simplify, we ignore potential differences in the acreage response to transitory and permanent price shocks due to differences in the short-run and long-run cost structures of the farm.
}

when the changes in prices are transitory. Direct and counter-cyclical payments do not distort the expected revenues in the current year since farmers cannot alter their base in the current year. On the other hand, loan deficiency payments can distort the expected revenues in the current year. Loan deficiency payments partially offset changes in total expected revenue (i.e., market revenue and government revenue) when market prices change, so equations (19) and (20) are less than one, and loan deficiency payments dampen the acreage response to market price.

Case 2. If changes in market prices in the current year are perceived to be permanent, then the acreage elasticities with respect to market prices in the presence of government payments (denoted $\hat{\varepsilon}^{c c}$ and $\hat{\varepsilon}^{c s}$ ) relative to the structural elasticities are as follows (see online appendix for derivation):

$$
\begin{aligned}
\frac{\hat{\varepsilon}^{c c}}{\varepsilon^{c c}}=1 & +\frac{\partial E_{0} \eta^{c}\left(\tilde{p}_{0}^{c}\right)}{\partial p^{c}} \\
& +\frac{\bar{\delta} \frac{\partial \Psi_{f}^{c}}{\partial p^{c}}+\bar{\delta}(1-\mu-\bar{\delta}) \frac{\partial \Psi_{F}^{c}}{\partial p^{c}}}{\bar{y}^{c}}, \\
\frac{\hat{\varepsilon}^{c s}}{\varepsilon^{c s}}=1 & +\frac{\partial E_{0} \eta^{s}\left(\tilde{p}_{0}^{s}\right)}{\partial p^{s}} \\
& +\frac{\bar{\delta} \frac{\partial \Psi_{f}^{s}}{\partial p^{s}}+\bar{\delta}(1-\mu-\bar{\delta}) \frac{\partial \Psi_{F}^{s}}{\partial p^{s}}}{\bar{y}^{s}},
\end{aligned}
$$

where

$$
\begin{aligned}
& \frac{\partial \Psi_{f}^{j}}{\partial p^{j}}=\sum_{t=f}^{F-1} \frac{\partial E_{0} \theta^{j}\left(\tilde{p}_{t}^{j}\right)}{\partial p^{j}} B Y_{f}^{j} \frac{\partial B A_{f}^{j}}{\partial a_{0}^{j}} \\
& \frac{\partial \Psi_{F}^{j}}{\partial p^{j}}=\sum_{t=F}^{T} \beta^{t} \frac{\partial E_{0} \theta^{j}\left(\tilde{p}_{t}^{j}\right)}{\partial p^{j}} B Y_{f}^{j} \frac{\partial B A_{f}^{j}}{\partial a_{0}^{j}}
\end{aligned}
$$

where $p^{j}$ is the expected price of crop $j$ in all future years formed at the time of planting in the current year.

In case 2 , the derivatives are with respect to a change in the expected price in all future years, since the change in price is permanent. The third terms in equations (21) and (22) account for the effect of expected base updating on acreage response to market price. Note that the expected payment rate $E_{0} \theta^{j}\left(\tilde{p}_{t}^{j}\right)$ only depends on market prices due 
to counter-cyclical payments, so direct payments do not affect the acreage response to market price through expected base updating. Thus, $\frac{\partial \Psi_{f}^{j}}{\partial p^{j}}$ is the present value of the change in expected marginal counter-cyclical payments from a permanent change in the market price during farm bill $f$ if base is updated in farm bill $f$. Similarly, $\frac{\partial \Psi_{F}^{j}}{\partial p^{j}}$ is the present value of the change in expected marginal counter-cyclical payments from a permanent change in the market price during farm bill $F$ if base is updated in farm bill $f$, but is not updated in farm bill $F$. The third terms in equations (21) and (22) give the change in expected marginal counter-cyclical payments relative to the change in expected marginal market revenue (i.e., expected yield) from a price increase.

If a change in the market price is perceived to be permanent, then the change affects a farmer's expectation of the future counter-cyclical payment rate. Expected future counter-cyclical payments partially offset the change in expected market revenue when market prices change, and these future counter-cyclical payments are linked to current acreage decisions through expected base updating. Thus, counter-cyclical payments will dampen acreage response to market price in the presence of expected base updating.

Note that government payments dampen both the acreage response to own-price and acreage response to cross-price. If marginal government payments are larger for the alternative crop, then the decrease (in absolute value) of the cross-price elasticity will be larger than the decrease in the own-price elasticity. Thus, government payments not only affect the response to own-price, but also the amount of substitution between crops in response to changes in market demand.

\section{Numerical Simulations}

We use the analytical results in the previous section to simulate the effect of expected base updating on corn and soybean production in Iowa, Illinois, and Indiana. The online appendix contains a script to replicate our numerical simulations using the open source $\mathrm{R}$ software. Parameter values used in the simulations are given in table 1.
A discount factor of 0.95 is used. ${ }^{7}$ It is assumed that farm bill $f$ is implemented one year from the current year and lasts for six years, then farm bill $F$ is implemented for another six years. Average prices are the average 2006-2010 marketing year average prices at the national level. We calculate the yield for Iowa, Illinois, and Indiana for each year by taking the total production across the three states, and dividing by total harvested acres using National Agricultural Statistics Service state-level data. Average yields are the average 2006-2010 yields for the three states.

If base is updated, then it is assumed that base acres in the next farm bill are calculated from a four-year average of previous planted acreage that includes acreage in the current year such that $\frac{\partial B A_{f}^{j}}{\partial a_{0}^{j}}=0.25$. We assume that base yields are also updated. Updated base yields are the 2006-2010 average yield, multiplied by a discount factor of 0.935 . In the 2002 update of base, if farmers updated base acres, then they could update countercyclical base yields with a discount factor of 0.935. If farmers expect that base updating will be voluntary, or expect to only update counter-cyclical base yields, then our simulations overestimate the effect of expected base updating. Again, we do not intend to model a specific historical scenario.

In the simulations, we vary farmers' perceived probability of base updating between 0 and 1 . If the probability of base updating is positive, then we assume that the probability of the programs ending is zero. If the probability of base updating is zero, then the simulation results may be interpreted as either (a) the effect with direct and counter-cyclical payments continuing with no expected base updating, or $(b)$ the effect with a $100 \%$ probability of direct and counter-cyclical payments ending.

The cross-price elasticity is likely to be negative and large relative to the own-price elasticity for corn and soybeans since the crops are commonly grown in rotation in Iowa, Illinois, and Indiana, and there is typically little change in total acres planted to the crops. The cross-price elasticity is likely to be larger for soybean acreage because corn is typically the more profitable crop in the rotation, and soybeans are grown to capture

\footnotetext{
${ }^{7}$ This implies an interest rate of $5.26 \%$.
} 
Table 1. Parameter Values Used in the Simulations

\begin{tabular}{|c|c|c|}
\hline Parameter & Description & Value(s) \\
\hline \multicolumn{3}{|c|}{ Fixed Parameters } \\
\hline$\beta$ & Discount rate & 0.95 \\
\hline$f$ & Years to first farm bill & 1 \\
\hline$F$ & Years to second farm bill & 7 \\
\hline$T$ & End of second farm bill & 12 \\
\hline $\bar{p}^{c}$ & Average price of corn & 4.01 \\
\hline $\bar{p}^{s}$ & Average price of soybeans & 8.84 \\
\hline $\bar{y}^{c}$ & Average corn yield & 168 \\
\hline $\bar{y}^{s}$ & Average soybean yield & 48 \\
\hline \multicolumn{3}{|c|}{ 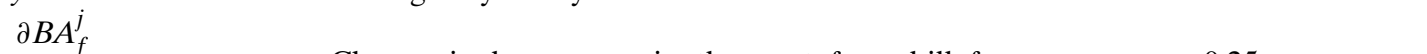 } \\
\hline$\overline{\partial A_{0}^{j}}$ & $\begin{array}{l}\text { Change in base acres in the next farm bill from } \\
\text { an increase in acres planted in the current year } \\
\text { conditional on updating occurring }\end{array}$ & 0.25 \\
\hline$B Y_{f}^{c}$ & Updated base yield for corn & 157 \\
\hline$B Y_{f}^{s}$ & Updated base yield for soybeans & 45 \\
\hline$\lambda$ & Discount factor for base payments & 0.85 \\
\hline$D^{c}$ & Direct payment rate for corn & 0.28 \\
\hline$T P^{c}$ & Target price for corn & 2.63 \\
\hline$L R^{c}$ & Loan rate for corn & 1.95 \\
\hline$D^{s}$ & Direct payment rate for soybeans & 0.44 \\
\hline$T P^{s}$ & Target price for soybeans & 5.80 \\
\hline$L R^{s}$ & Loan rate for soybeans & 5.00 \\
\hline \multicolumn{3}{|c|}{ Varying Parameters } \\
\hline $\bar{\delta}$ & Probability of base updating & {$[0,1]$} \\
\hline$\mu$ & $\begin{array}{l}\text { Probability of direct and counter-cyclical payments } \\
\text { ending }\end{array}$ & $\{0,1\}$ \\
\hline$\frac{\varepsilon^{c s}}{\varepsilon^{c c}}$ & $\begin{array}{l}\text { Ratio of cross-price to own-price elasticity for corn } \\
\text { acreage }\end{array}$ & $\{-0.75,0\}$ \\
\hline$\frac{\varepsilon^{s c}}{\varepsilon^{s s}}$ & $\begin{array}{l}\text { Ratio of cross-price to own-price elasticity for } \\
\text { soybean acreage }\end{array}$ & $\{-1.25,0\}$ \\
\hline$E_{0} \theta^{c}\left(\tilde{p}_{t}^{c}\right)$ & Expected base payment rate for corn & $\{0.44,0.24\}$ \\
\hline$E_{0} \theta^{s}\left(\tilde{p}_{t}^{s}\right)$ & Expected base payment rate for soybeans & $\{0.54,0.37\}$ \\
\hline$\frac{\partial E_{0} \theta^{c}\left(\tilde{p}_{t}^{c}\right)}{\partial p^{c}}$ & $\begin{array}{l}\text { Change in expected base payment rate for corn } \\
\text { from a permanent change in price }\end{array}$ & $\{-0.232,-0.002\}$ \\
\hline$\frac{\partial E_{0} \theta^{s}\left(\tilde{p}_{t}^{s}\right)}{\partial p^{s}}$ & $\begin{array}{l}\text { Change in expected base payment rate for } \\
\text { soybeans from a permanent change in price }\end{array}$ & $\{-0.091,-0.002\}$ \\
\hline
\end{tabular}

Note: In the "low-price" scenario, the mean of the distribution of anticipated prices during future legislation is $\$ 2.00$ for corn and $\$ 5.00$ for soybeans, corresponding to the larger expected base payment rates and larger changes in the expected base payments from a change in price. In the "highprice" scenario, the mean of the distribution of anticipated prices during future legislation is $\$ 5.00$ for corn and $\$ 12.50$ for soybeans, corresponding to the smaller expected base payment rates and smaller changes in the expected base payments from a change in price.

benefits from rotating the crops. For our estimates of the ratio of elasticities, we use recent econometric evidence by Hendricks, Smith, and Sumner (2013) that indicates the ratio is about -0.75 for corn acreage and about -1.25 for soybean acreage. ${ }^{8}$ We also

\footnotetext{
${ }^{8}$ Miller and Plantinga (1999) estimate that the ratio is about -0.4 for corn acreage, and about -1 for soybean acreage. Chavas and Holt (1996) estimate that the ratio is about -0.5 for corn acreage, and about -2 for soybean acreage.
}

present simulation results with an elasticity ratio of zero to provide estimates if changes in returns to the alternative crop from base updating are ignored.

Since the base payment rate, $\theta^{j}\left(\tilde{p}_{t}^{j}\right)$, is nonlinear in prices, we simulate its expected value. Note that the relevant parameter is the expected direct and counter-cyclical payment rate in periods governed by future legislation, rather than the expected payment rate in the current period. We assume that 
anticipated prices during future legislation are distributed lognormally. To estimate the volatility of prices across several years, we calculate the standard deviation of the logarithm of marketing-year-average prices from 1990 to 2010. We consider two scenarios for mean prices: $(a)$ "low prices" with the mean price of corn equal to $\$ 2.00 / \mathrm{bu}$ and the mean price of soybeans equal to $\$ 5.00 / \mathrm{bu}$, and $(b)$ "high prices" with the mean price of corn equal to $\$ 5.00 / \mathrm{bu}$ and the mean price of soybeans equal to $\$ 12.50 / \mathrm{bu}$. For each price scenario, we randomly draw 10,000 prices from a lognormal distribution and calculate $\theta^{j}\left(\tilde{p}_{t}^{j}\right)$ from equation (3) using policy parameters from the 2002 and 2008 Farm Bills, and reported in table 1 . In the low-price scenario, we estimate that the average base payment (per bushel of base) is $\$ 0.44$ for corn and $\$ 0.54$ for soybeans. In the high-price scenario, we estimate that the average base payment rate is $\$ 0.24$ for corn and $\$ 0.37$ for soybeans.

It could be argued that "higher" prices are likely to be the new normal due to several factors including increased meat demand, slowing productivity growth, and increased biofuel production. We argue, however, that the low-price scenario is still relevant because it represents a scenario where the target price is greater than the effective price (i.e., direct payment rate plus the higher of the market price and the loan rate). Alternatively, we could simulate a scenario with high market prices and higher target prices.

We also simulate the change in the expected base payment rate from a permanent change in price, $\frac{\partial E_{0} \theta^{j}\left(\tilde{p}_{t}^{j}\right)}{\partial p^{j}}$. For each price scenario, we decrease the mean price by $\$ 0.10$, then randomly draw 10,000 new prices to estimate the new expected value of the base payment rate. The change in the mean base payment rate divided by the change in mean price is our estimate of $\frac{\partial E_{0} \theta^{j}\left(\tilde{p}_{t}^{j}\right)}{\partial p^{j}}$. In the low-price scenario, we estimate that the base payment rate increases by $\$ 0.023$ for corn and $\$ 0.009$ for soybeans with respect to a permanent \$0.10 decrease in the mean price. In the high-price scenario, we estimate that the change in the base payment rate with respect to a permanent change in price is negligible for corn and soybeans. When the mean of anticipated prices in the future is high, expected counter-cyclical payments are very small, so a change in the mean price has a negligible effect on expected counter-cyclical payments.

\section{Numerical Results for the Effect on Crop Acreage}

Results for the effect of base updating on corn acreage are presented in figure 1 . We present the results as the percentage change in corn acreage from expected base updating relative to the percent change in corn acreage that would occur from a $100 \%$ increase in the price of corn, calculated using equation (18). Results for the effect on soybean acreage are presented in figure 2. The effect of base updating on soybean acreage is obtained by reversing the corn and soybean indices in equation (18).

The $\mathrm{x}$-axis in figures 1 and 2 varies the probability of base updating occurring in future farm bills. The solid line indicates results with a ratio of the cross-price and own-price elasticity consistent with recent econometric estimates. The dashed line indicates results with a zero cross-price elasticity. The top panel provides results for a low-price scenario and the bottom panel gives results for a high-price scenario.

The degree of coupling is concave in the probability of base updating. If farmers perceive a large probability of base updating, then they are likely to expect that the stream of benefits from changing current acreage will not last long because base is likely to be updated again in the farm bill after the next one. The effect of base updating is larger (in absolute value) in the low-price scenario than the high-price scenario because expected counter-cyclical payments are larger in the low-price scenario. That is, larger future government payments are captured by altering current acreage in the low-price scenario.

Under all of the parameter combinations considered, expected base updating has a positive effect on corn acreage. The effect of base updating on soybean acreage, however, is negative when the ratio of the cross-price elasticity to own-price elasticity is -1.25 . Expected base updating has a negative effect on soybean acreage because corn base receives a larger payment than soybean base. Farmers will increase corn acreage to increase future payments, but a large negative cross-price elasticity indicates that they will decrease soybean acreage.

The results with a zero cross-price elasticity reflect the effect of expected base updating on crop acreage, but neglecting to account for the alternative program crop. If the alternative program crop is ignored, the effect of expected base updating on corn acreage 


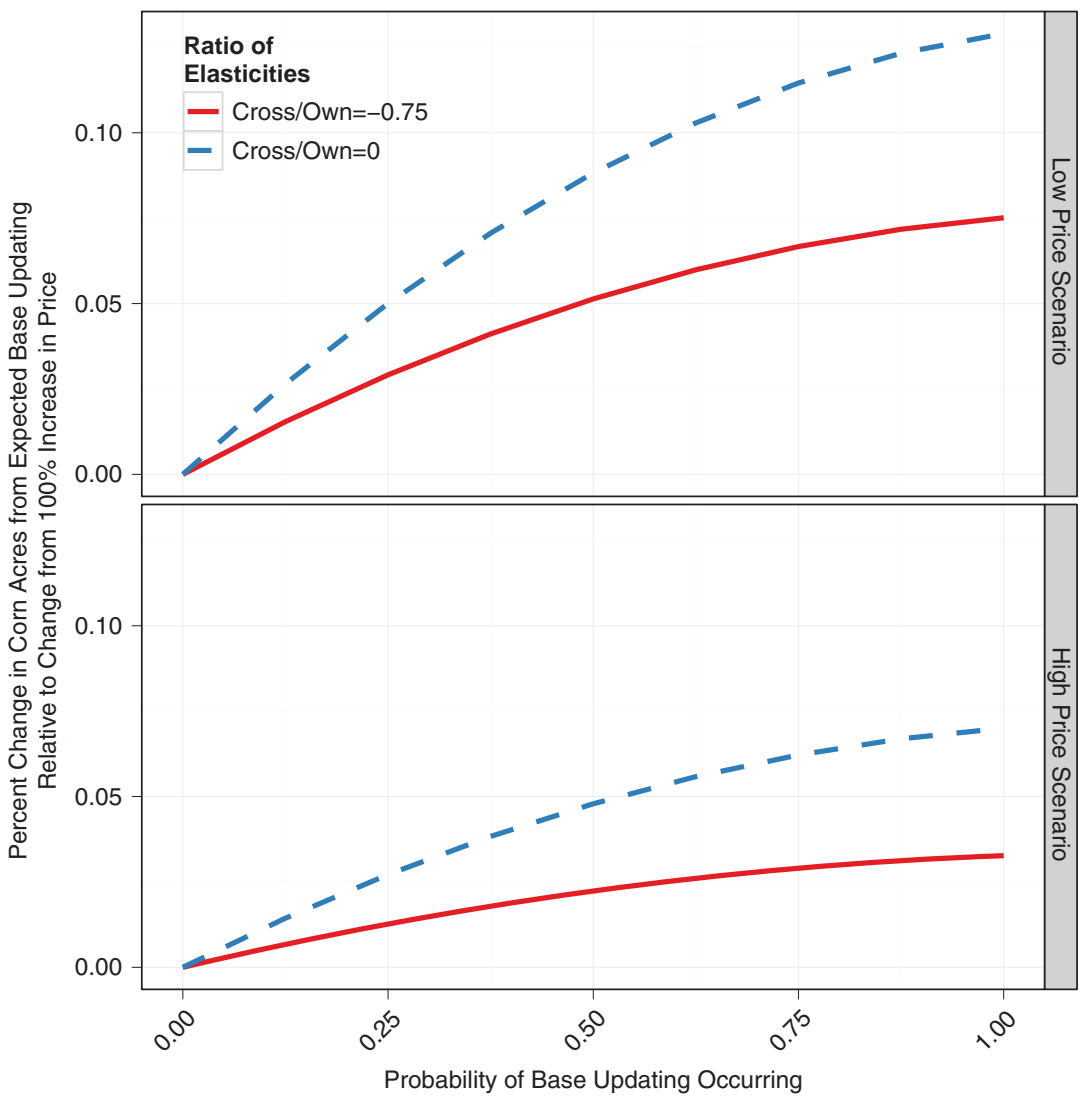

Figure 1. The effect of expected base updating on corn acreage

Note: The graphs indicate the percentage change in corn acres from expected base updating relative to the percentage change in corn acres that would occur from a $100 \%$ increase in the price of corn calculated from equation (18). The x-axis varies the probability of base updating occurring The solid line indicates results with a ratio of the cross-price and own-price elasticity consistent with recent econometric estimates. The dashed line indicates results with a zero cross-price elasticity.

is overestimated by $72 \%$ in the low-price scenario, and by $114 \%$ in the high-price scenario. ${ }^{9}$ The effect of expected base updating on soybean acreage is of the opposite sign-but nearly the same magnitude - if the alternative program crop is ignored.

The effect of expected base updating on corn and soybean acreage is relatively small, even for parameters that we think will overestimate the effect. For example, if we assume low prices, that the probability of base updating is 0.50 , and that there is a cross-price to own-price elasticity ratio of -0.75 , then the increase in corn acres due to expected base updating is $5.1 \%$ as large as the increase in acres from a $100 \%$ increase in

\footnotetext{
${ }^{9}$ The difference between the price scenarios is that the relative base payments between corn and soybeans differ between the price scenarios, since counter-cyclical payments are larger in the low-price scenario.
}

the price of corn. Assuming the same parameters for soybean acreage, but a cross-price to own-price elasticity ratio of -1.25 , then the decrease in soybean acres is $6.1 \%$ as large as the increase in acres from a $100 \%$ increase in the price of soybeans. If the corn and soybean own-price elasticities are 0.3 , then expected base updating leads to a $1.5 \%$ increase in corn acres, and a $1.8 \%$ decrease in soybean acres at low prices. Assuming the same parameter values but high prices, base updating increases corn acreage by $0.7 \%$, and decreases soybean acreage by $0.8 \%$.

The estimates of changes in corn and soybean acreage due to expected base updating can be interpreted as the change in acres compared to a scenario of no base updating, and direct and counter-cyclical payments are expected to continue $(\bar{\delta}=0, \mu=0)$ compared to a scenario where direct and counter-cyclical payments are expected to 


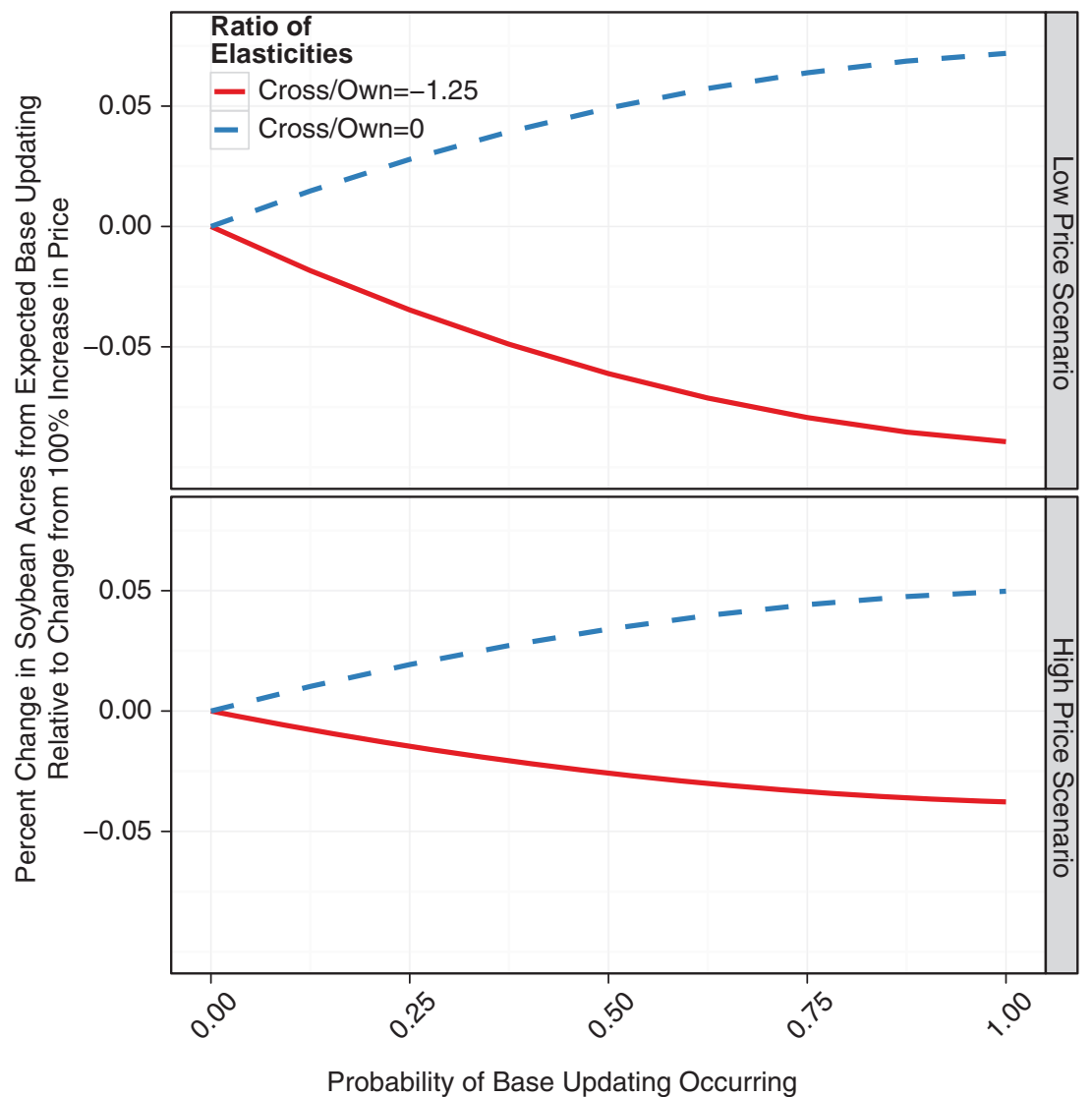

Figure 2. The effect of expected base updating on soybean acreage

Note: The graphs indicate the percentage change in soybean acres from expected base updating relative to the percentage change in soybean acres that would occur from a $100 \%$ increase in the price of soybeans calculated by reversing the corn and soybean indices in equation (18). The $\mathrm{x}$-axis varies the probability of base updating occurring. The solid line indicates results with a ratio of the cross-price and own-price elasticity consistent with recent econometric estimates. The dashed line indicates results with a zero cross-price elasticity.

end $(\bar{\delta}=0, \mu=1)$. Policy discussions in 2012 and 2013 suggest that direct payments are likely to be eliminated in the next farm bill and replaced with a revenue insurance program more closely tied to actual production. Prior to this, farmers may have expected direct and counter-cyclical payments to continue with potential base updating. ${ }^{10}$ Our results indicate that a revision of policy expectations from potential base updating to an expectation that the programs would end leads to a decrease in corn acreage, and an increase in soybean acreage before the

${ }^{10}$ We do not attempt to provide a precise date when policy expectations may have changed. next farm bill-albeit by less than $1 \%$ in the high-price scenario. ${ }^{11}$

\section{Numerical Results for the Effect on Acreage Response to Price}

Results for the effect of expected base updating on corn acreage response to permanent changes in market prices are presented in figures 3 and 4. Figure 3 gives the own-price elasticity with expected base updating relative to the structural own-price elasticity, calculated with equation (21) and setting the effect of loan deficiency payments equal to

\footnotetext{
${ }^{11}$ This assumes that farmers do not expect payments in the new program to depend on planted acreage during the previous farm bill.
} 


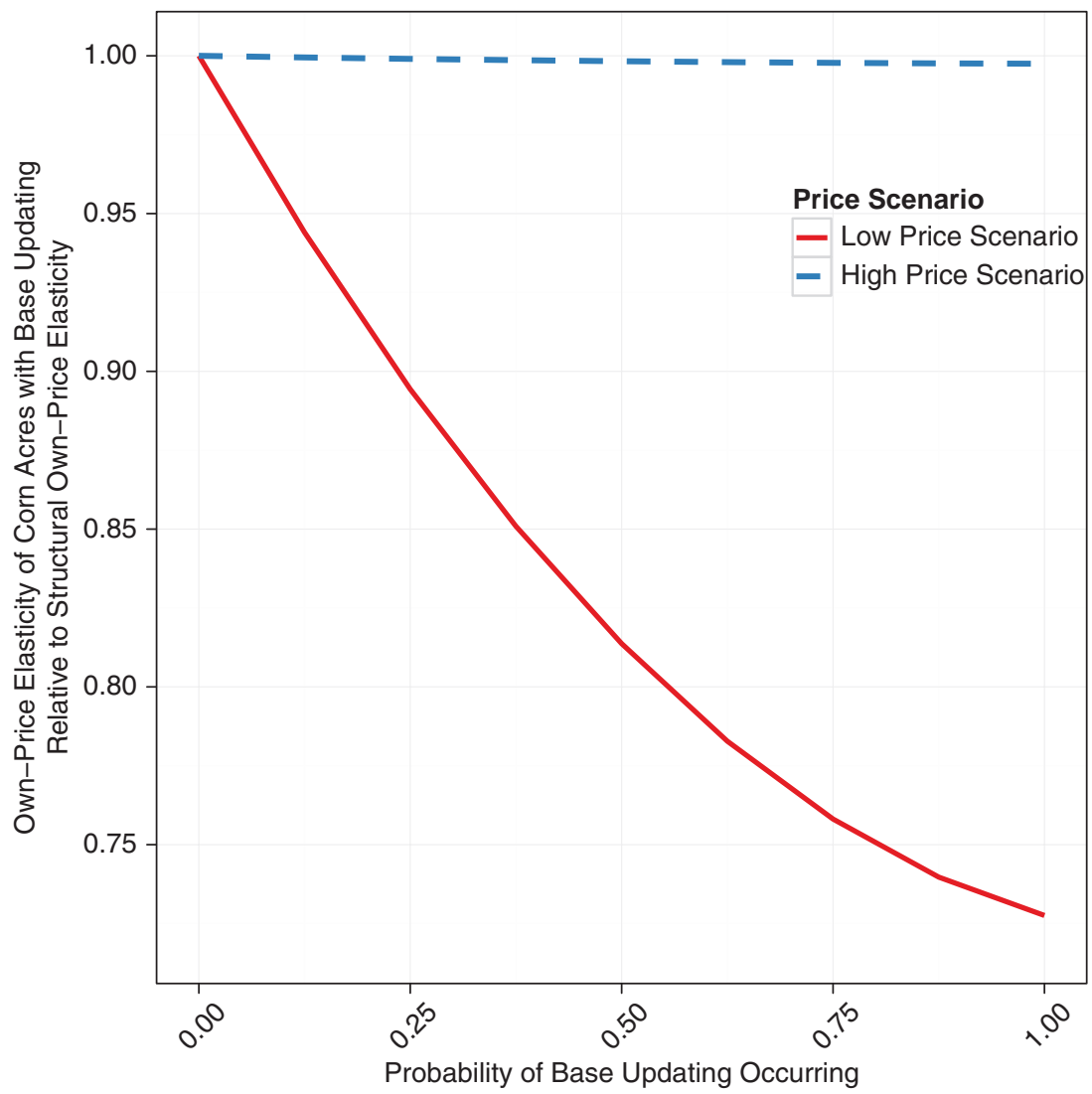

\section{Figure 3. Own-price elasticity of corn acreage with expected base updating relative to structural own-price elasticity}

Note: The graphs provide the own-price elasticity of corn acreage with expected base updating relative to the structural own-price elasticity-calculated with equation (21) and setting the effect of loan deficiency payments equal to zero. The x-axis in each plot varies the probability of base updating occurring. The solid line indicates results for a low-price scenario, and the dashed line indicates results for a high-price scenario.

zero. Figure 4 provides the cross-price elasticity with expected base updating relative to the structural cross-price elasticity, calculated with equation (22) and setting the effect of loan deficiency payments equal to zero. If a change in price is viewed as transitory, then expected base updating will have no effect on acreage response to market price. Thus, we view the results in figures 3 and 4 as the largest effect on supply response to price that is plausible from expected base updating. We set the effect of loan deficiency payments equal to zero $\left(\frac{\partial E_{0} \eta^{j}\left(\tilde{p}_{0}^{j}\right)}{\partial p^{j}}=0\right)$ to isolate the effect of expected base updating on supply response to price, not because the effect of loan deficiency payments is unimportant.
The $\mathrm{x}$-axis in figures 3 and 4 varies the probability of base updating occurring in future farm bills. The solid line indicates results for a low-price scenario, while the dashed line indicates results for a high-price scenario. Note that the effects in equations (21) and (22) do not depend on the ratio of the cross-price elasticity to the own-price elasticity.

In the low-price scenario, expected base updating dampens corn acreage own-price response (figure 3) because expected future counter-cyclical payments partially offset the change in expected market revenue, and these future counter-cyclical payments are linked to current acreage decisions through expected base updating. Expected base 


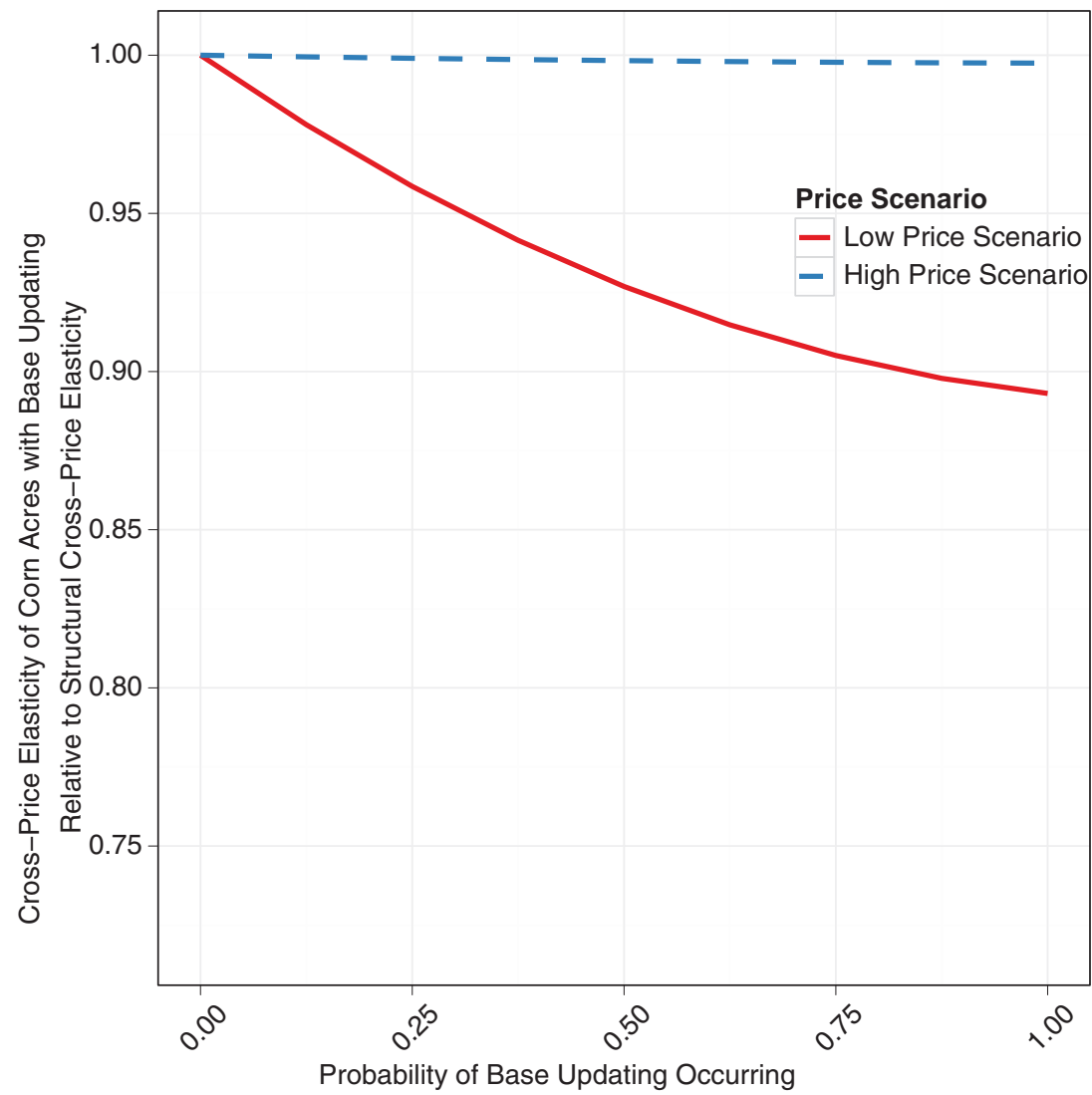

Figure 4. Cross-price elasticity of corn acreage with expected base updating relative to structural cross-price elasticity

Note: The graphs illustrate the cross-price elasticity of corn acreage with expected base updating relative to the structural cross-price elasticity - calculated with equation (22) and setting the effect of loan deficiency payments equal to zero. The $\mathrm{x}$-axis in each plot varies the probability of base updating occurring. The solid line indicates results for a low-price scenario and the dashed line indicates results for a high-price scenario.

updating also dampens corn acreage crossprice response (figure 4), since changes in soybean prices are also offset by countercyclical payments for soybean base. Ignoring the multicrop context ignores the effect of expected base updating on cross-price elasticities. In the high-price scenario, expected base updating has a negligible effect on own-price and cross-price acreage responses because expected counter-cyclical payments are negligible.

For corn acreage, expected base updating has a larger dampening effect on own-price elasticity than the cross-price elasticity, while for soybean acreage, expected base updating has a smaller dampening effect on the ownprice elasticity than the cross-price elasticity (results not shown). Expected base updating has a larger dampening effect on changes in corn prices than soybean prices because the expected counter-cyclical payments are relatively larger for corn.

Assuming that the probability of base updating is 0.5 and a low-price scenario, the corn acreage own-price elasticity is $81 \%$ of the structural own-price elasticity, and the cross-price elasticity is $93 \%$ of the structural cross-price elasticity. Note, however, that these estimates assume a permanent change in market price, and expected base updating has no effect on supply response to price when changes in market prices are transitory. Since many price changes are likely to be perceived as transitory and prices have recently been high, econometric models that seek to estimate structural supply response with recent data are not likely to have substantial bias due to base updating. 


\section{Conclusion}

This article considers the effect of expectations about future policy on the acreage of program crops. The full effect of an expected change in policy on program crop acreage is best understood in a multicrop context because farmers would most likely expect that a change in policy would be implemented for all relevant program crops, and program crops are often substitutes or complements in production. We illustrate the importance of placing the model in a multicrop context by considering the effects of expected base updating on corn and soybean production in the Corn Belt of the United States.

Recent policy discussions in the United States and Europe suggest that direct payments may be reduced or eliminated in favor of more revenue insurance. Our results indicate that such policy expectations lead to a decrease in corn acreage and an increase in soybean acreage. Further, our results have implications for understanding the effect of these policy changes on trade distortionsand therefore the welfare of farmers in developing countries (Babcock and Paulson 2012). We find that for corn and soybeans, direct payments likely have a relatively small acreage impact, and thus the shift towards revenue insurance will likely increase trade distortions.

Our results emphasize the importance of considering the multicrop nature of agricultural production and policy expectations as they relate to the implications of anticipated policy changes. For example, even though soybeans are a program crop, corn has a larger base payment rate and the two crops are substitutes in production. Our numerical simulations indicate that expected base updating - as applied by the United States-has limited effects on corn and soybean acreage. The effect of expected base updating has likely been larger, however, for cotton and rice, which have had large direct and counter-cyclical payment rates relative to payment rates of alternative crops, and which are often grown in regions with less direct substitution with other program crops. The effect of base updating on wheat and sorghum production may have been larger as well. Substitution with other program crops is likely smaller for wheat and sorghum because competing land uses such as alfalfa, fallow, and pasture are not eligible for program payments.

We also find that expected base updating dampens both the own-price and cross-price acreage responses. The numerical simulations, however, indicate small differences between the acreage response to price with expected base updating and the structural acreage response to price, since base updating only affects market response to price if changes in current prices are perceived as permanent. In contrast, McDonald and Sumner (2003) found that response to market price was onethird to one-fourth of the structural response for rice under an acreage reduction program implemented prior to 1996. Chavas and Holt (1990), among others, proposed methods to account for the effect of the loan rate on the distribution of anticipated prices, but other government programs have proven more difficult to account for in econometric work. Our results indicate that post-1996 data may provide the best period in recent history to estimate supply elasticities in the United States that are close to structural elasticities.

\section{References}

Ahearn, M.C., H. El-Osta, and J. Dewbre. 2006. The Impact of Coupled and Decoupled Government Subsidies on Off-farm Labor Participation of U.S. Farm Operators. American Journal of Agricultural Economics 88: 393-408.

Antón, J., and C.L. Mouël. 2004. Do Countercyclical Payments in the 2002 US Farm Act Create Incentives to Produce? Agricultural Economics 31: 277-284.

Babcock, B., and N. Paulson. 2012. Potential Impact of Proposed 2012 Farm Bill Commodity Programs on Developing Countries. Issue Paper No. 45, International Centre for Trade and Sustainable Development.

Berry, S., and W. Schlenker. 2011. Technical Report for the ICCT: Empirical Evidence on Crop Yield Elasticities. http://www.theicct.org/sites/default/files/ publications/berry_schlenker_cropyield elasticities_sep2011.pdf.

Bhaskar, A., and J.C. Beghin. 2010. Decoupled Farm Payments and the Role of Base Acreage and Yield Updating Under Uncertainty. American Journal of Agricultural Economics 92: 849-858. 
Chau, N.H., and H. de Gorter. 2005. Disentangling the Consequences of Direct Payment Schemes in Agriculture on Fixed Costs, Exit Decisions, and Output. American Journal of Agricultural Economics 87: 1174-1181.

Chavas, J.P., and M.T. Holt. 1990. Acreage Decisions under Risk: The Case of Corn and Soybeans. American Journal of Agricultural Economics 72: 529-538.

1996. Economic Behavior under Uncertainty: A Joint Analysis of Risk Preferences and Technology. The Review of Economics and Statistics 78: 329-335.

Coble, K.H., J.C. Miller, and M.D. Hudson. 2008. Decoupled Farm Payments and Expectations for Base Updating. Applied Economic Perspectives and Policy 30: 27-42.

de Gorter, H., and E.O. Fisher. 1993. The Dynamic Effects of Agricultural Subsidies in the United States. Journal of Agricultural and Resource Economics 18: 147-159.

Farm Service Agency. 2008. Direct and Counter-Cyclical Payment Program Fact Sheet. http://www.apfo.usda.gov/Internet/ FSA_File/dcp2008.pdf.

Feng, H., and B.A. Babcock. 2010. Impacts of Ethanol on Planted Acreage in Market Equilibrium. American Journal of Agricultural Economics 92: 789-802.

Girante, M.J., B.K. Goodwin, and A. Featherstone. 2008. Farmer's Crop Acreage Decisions in the Presence of Credit Constraints: Do Decoupled Payments Matter? Paper presented at AAEA annual meeting, Orlando, FL.

Goodwin, B.K., M. Marra, N. Piggott, and S. Mueller. 2012. Is Yield Endogenous to Price? An Empirical Evaluation of Inter- and Intra-seasonal Corn Yield Response. Paper presented at AAEA annual meeting, Seattle, WA.

Goodwin, B.K., and A.K. Mishra. 2005. Another Look at Decoupling: Additional Evidence on the Production Effects of Direct Payments. American Journal of Agricultural Economics 87: 1200-1210.

- 2006. Are Decoupled Farm Program Payments Really Decoupled? An Empirical Evaluation. American Journal of Agricultural Economics 88: 73-89.

Hendricks, N.P., A. Smith, and D.A. Sumner. 2013. Crop Supply Dynamics and the Illusion of Partial Adjustment. http://nphendricks.com/work-in-progress/.
Hennessy, D.A. 2006. On Monoculture and the Structure of Crop Rotations. American Journal of Agricultural Economics 88: 900-914.

- 1998. The Production Effects of Agricultural Income Support Policies under Uncertainty. American Journal of Agricultural Economics 80: 46-57.

Houck, J.P., and M.E. Ryan. 1972. Supply Analysis for Corn in the United States: The Impact of Changing Government Programs. American Journal of Agricultural Economics 54: 184-191.

Just, D.R. 2011. Calibrating the Wealth Effects of Decoupled Payments: Does Decreasing Absolute Risk Aversion Matter? Journal of Econometrics, Annals of Econometrics 162: 25-34.

Just, D.R., and J.D. Kropp. 2013. Production Incentives from Static Decoupling: Land Use Exclusion Restrictions. American Journal of Agricultural Economics 95: 1049-1067.

Key, N., and M.J. Roberts. 2009. Nonpecuniary Benefits to Farming: Implications for Supply Response to Decoupled Payments. American Journal of Agricultural Economics 91: 1-18.

Kydland, F.E., and E.C. Prescott. 1977. Rules Rather than Discretion: The Inconsistency of Optimal Plans. Journal of Political Economy 85: 473-492.

Lee, D.R., and P.G. Helmberger. 1985. Estimating Supply Response in the Presence of Farm Programs. American Journal of Agricultural Economics 67: 193-203.

Lin, W., and R. Dismukes. 2007. Supply Response under Risk: Implications for Counter-cyclical Payments' Production Impact. Review of Agricultural Economics 29: 64-86.

McDonald, J.D., and D.A. Sumner. 2003. The Influence of Commodity Programs on Acreage Response to Market Price: With an Illustration concerning Rice Policy in the United States. American Journal of Agricultural Economics 85: 857-871.

McIntosh, C.R., J.F. Shogren, and E. Dohlman. 2007. Supply Response to Countercyclical Payments and Base Acre Updating under Uncertainty: An Experimental Study. American Journal of Agricultural Economics 89: 1046-1057.

Miller, D.J., and A.J. Plantinga. 1999. Modeling Land Use Decisions with Aggregate Data. American Journal of Agricultural Economics 81: 180-194. 
Muth, R.F. 1964. The Derived Demand Curve for a Productive Factor and the Industry Supply Curve. Oxford Economic Papers 16: 221-234.

O'Donoghue, E.J., and J.B. Whitaker. 2010. Do Direct Payments Distort Producers' Decisions? An Examination of the Farm Security and Rural Investment Act of 2002. Applied Economic Perspectives and Policy 32: 170-193.

Roe, T., A. Somwaru, and X. Diao. 2002. Do Direct Payments have Intertemporal Effects on U.S. Agriculture? Trade and Macroeconomics Division Discussion Paper No. 104, International Food Policy Research Institute.

Serra, T., B.K. Goodwin, and A.M. Featherstone. 2011. Risk Behavior in the Presence of Government Programs.
Journal of Econometrics, Annals of Econometrics 162:18-24.

Sumner, D.A. 2003. Implications of the U.S. Farm Bill of 2002 for Agricultural Trade and Trade Negotiations. Australian Journal of Agricultural and Resource Economics 47: 99-122.

Weber, J.G., and N. Key. 2012. How much Do Decoupled Payments Affect Production? An Instrumental Variable Approach with Panel Data. American Journal of Agricultural Economics 94: 52-66.

Young, C.E., D.W. Skully, P.C. Westcott, and L. Hoffman. 2005. Economic Analysis of Base Acre and Payment Yield Designations under the 2002 U.S. Farm Act. Washington DC: U.S. Department of Agriculture, Economic Research Service, Economic Research Report No. 12. 